\title{
Facile Synthesis of Benzaldehyde-Functionalized Ionic Liquids and Their Flexible Functional Group Transformations
}

\author{
Qiang Huang and Baozhong Zheng \\ Department of Materials Science and Engineering, Yunnan University, Kunming 650091, China \\ Correspondence should be addressed to Qiang Huang, huangqiang@ynu.edu.cn \\ Received 5 August 2012; Revised 7 October 2012; Accepted 9 October 2012 \\ Academic Editor: Robert Engel
}

Copyright (๑) 2012 Q. Huang and B. Zheng. This is an open access article distributed under the Creative Commons Attribution License, which permits unrestricted use, distribution, and reproduction in any medium, provided the original work is properly cited.

Three benzaldehyde-functionalized ionic liquids were readily synthesized by quaternization of $N$-alkylimidazole with benzaldehyde-functionalized alkyl bromides under microwave irradiation in good yield. These aldehyde-functionalized ionic liquids could easily be oxidized in the presence of $\mathrm{H}_{2} \mathrm{O}_{2} / \mathrm{KOH}$ or be reduced by $\mathrm{NaBH}_{4}$ leading to the formation of the corresponding carboxyl-functionalized ionic liquids or benzylic alcohol-functionalized ionic liquids. In addition, the condensations of these functionalized ones with hydrazine hydrate and with aniline under reductive amination conditions were demonstrated.

\section{Introduction}

Ionic liquids (ILs) have received an increasing interest as green solvent systems in the fields of organic synthesis [1, 2], separation technologies [3], electrochemical devices [4], and materials chemistry $[5,6]$ because of their advantages over traditional molecular solvents including negligible vapor pressure, broad liquid range, properties modulation, nonflammability, high thermal stability, and so forth [79]. Recently, the scope of ILs has been expanded by the introduction of additional functional groups in the ionic liquid structure. These so-called task-specific ionic liquids [10] or a much larger family of task-specific onium salts [11] can be utilized as soluble supports for organic synthesis, supported reagents or catalysts [12], and scavengers in solution phase combinatorial synthesis $[13,14]$ with high affinity for the ionic liquid phase. Task-specific ionic liquids are compatible with a variety of organic transformations and have proven to be useful for the extraction of specific chemicals [15]. The applications of functionalized ILs for the synthesis of inorganic materials have also been reported by several groups in recent years [16, 17].

Aldehyde-functionalized ILs are important and widely used due to their diverse reactivity. They have been used as soluble supports for various organic reactions such as reductive amination [18], Knoevenagel [19], Biginelli [20], and multicomponent reactions $[21,22]$. In this work, we report the synthesis of three benzaldehyde-functionalized ionic liquids and their flexible functional group transformations under simple conditions.

\section{Results and Discussion}

2.1. Synthesis of Benzaldehyde-Functionalized Ionic Liquids. The syntheses of $N$-methylimidazolium based benzaldehydefunctionalized ionic liquids $(\mathbf{4 a}-\mathbf{c})$ were readily accomplished by alkylation of the phenols (1a-c) with 1,4dibromobutane (2) and subsequent substitution of benzaldehyde-functionalized alkyl bromides (3a-c) with $\mathrm{N}$ methylimidazole under microwave irradiation, respectively (Scheme 1). Benzaldehyde-functionalized imidazolium bromides $(4 \mathrm{a}-\mathrm{c}$ ) (obtained in the yields of $87 \%, 82 \%$, and $81 \%$ over the two steps with the purity of $93 \%, 97 \%$, and $95 \%$ based on HPLC, resp.) could be obtained by the routine postprocessing. They can be used as the ionic analogues of the known polymer supports of Wang-aldehyde resin, [23, 24], AMEBA [25], and 3-methoxy-4-benzyloxy benzaldehyde resins reported by our group recently [26], respectively. The intermediate products $(\mathbf{3} \mathbf{a}-\mathbf{c})$ were prepared by using microwave-assisted phase transfer catalytic technique for 


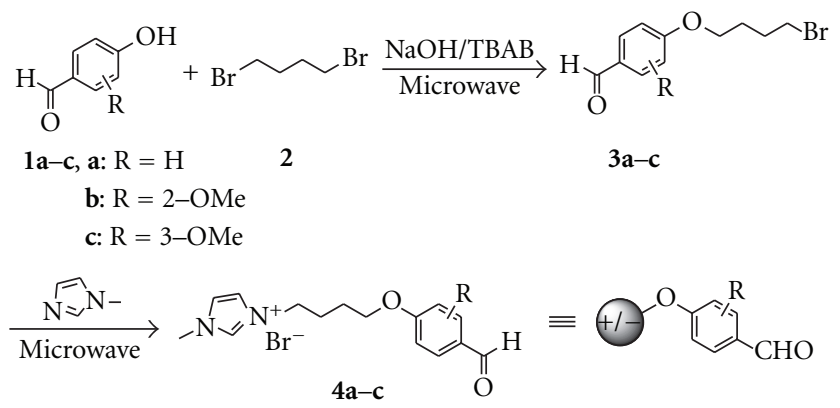

Scheme 1: The synthetic route of benzaldehyde-functionalized ionic liquids.

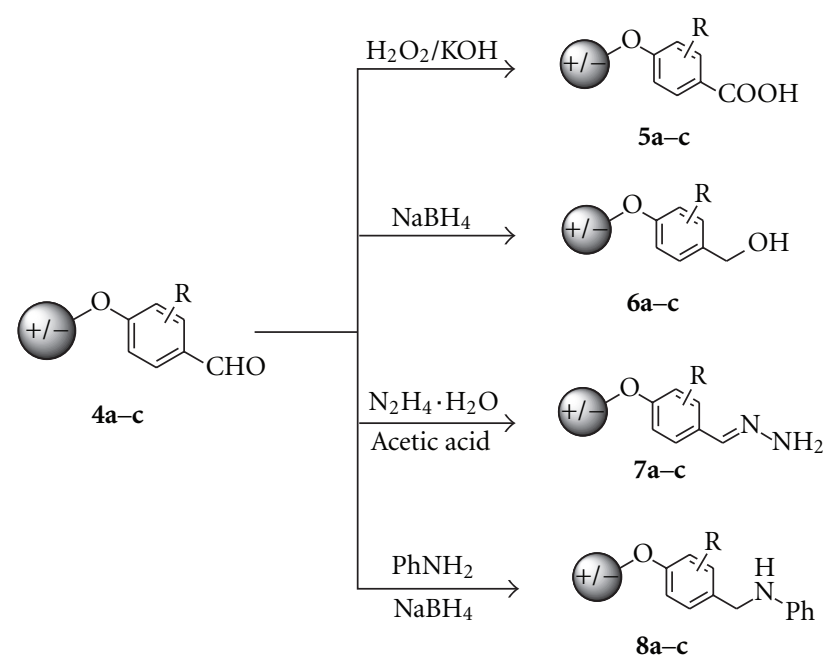

Scheme 2: The functional group transformational process of benzaldehyde-functionalized ionic liquids.

intensifying the Williamson ether synthetic process [27]. In the experiments, 1,4-dibromobutane was used as both a reagent and a solvent. Its high concentration and excessive dosage $(5: 1)$ could avoid the formation of $\alpha, \omega$-dialkyl compounds. The quaternization of $N$-methylimidazole was quantified under microwave irradiation and 98\% (4a), 97\% (4b), and 99\% (4c) yields were obtained, respectively. Shorter reactive time was required over that of the conventional heating [28].

The synthesis of functionalized ionic liquids is analogous to the corresponding nonfunctionalized ones. The same key steps can be applied depending on the nature of the cation and the anion. Quaternization of $N$-alkylimidazole with a functionalized alkyl halide usually affords the desired functionalized imidazolium halides in good yields. These salts can be further modified by ion metathesis, anion exchange with acids, or ion exchange resins.

2.2. Functional Group Transformation of Ionic Liquids. In order to illuminate the utility and flexibility of the aldehyde groups in ionic liquids in chemical transformation, some ionic analogue conversions were carried out. Aldehydefunctionalized ionic liquids $(\mathbf{4 a}-\mathbf{c})$ were readily oxidized by using an aq. $\mathrm{H}_{2} \mathrm{O}_{2} / \mathrm{KOH}$ green system. It afforded the carboxyl-functionalized ionic liquids $(5 \mathbf{a}-\mathbf{c})$ in a good yield (89\%). The oxidation of aromatic aldehydes to their corresponding carboxylic acids with a comparable yield under similar conditions has been reported by Cong and his coworkers [29]. The aldehyde groups in the ionic liquids was also reduced by utilizing conventional $\mathrm{NaBH}_{4}$ leading to the formation of the ionic products bearing benzylic alcohol $(\mathbf{6 a}-\mathbf{c})$. In addition, the ionic aldehyde compounds $(4 \mathbf{a}-\mathbf{c})$ were condensed with hydrazine hydrate in an acidic medium leading to the formation of the corresponding ionic hydrazone $(\mathbf{7 a}-\mathbf{c})$. They were also condensed with aniline under the reductive amination conditions using $\mathrm{NaBH}_{4}$ resulting in the formation of the ionic liquid-supported secondary amines $(\mathbf{8} \mathbf{a}-\mathbf{c})$. From the above-mentioned reactions represented in Scheme 2, it can be concluded that the ionic liquid-supported benzaldehydes are reactive enough towards many reagents and can therefore be used for many ionic analogue conversions.

\section{Conclusion}

In conclusion, three benzaldehyde-functionalized ionic liquids were readily synthesized by quaternization of $N$-alkylimidazole with benzaldehyde-functionalized alkyl halides under microwave irradiation in good yields. The aldehyde groups supported by the ionic compounds could 
conveniently be transformed to other reactive groups under conventional conditions. These aldehyde-functionalized ionic liquids can be used as task-specific ionic liquids or as intermediate products that can be converted to other functionalized ionic liquids and thus can have other more applications.

\section{Experimental}

All chemicals employed were commercially available analytical reagents and were directly used without further purification. Microwave reactions were conducted using a CEM Discover Synthesis Unit. Reactions were performed in glass vessels. Conventional heating reactions were performed using KEM-6 Parallel Synthesizer. Agilent 1100 was used for HPLC. FT-IR spectra ( $\mathrm{KBr}$ tableting) were recorded on Thermo Nicolet TFIR AVATAR 360. ${ }^{1} \mathrm{H}$-NMR spectra were recorded using Bruker AVANCE DRX500 spectrometer. The chemical shifts were recorded in parts per million $(\delta: \mathrm{ppm})$ referenced to TMS $(\delta: 0)$ as an internal standard and the coupling constants $(J)$ were given in $\mathrm{Hertz}(\mathrm{Hz})$.

\subsection{Syntheses and Characterization}

4.1.1. General Procedure for the Preparation of Compounds $(3 a-c)$. 4-Hydroxybenzaldehyde (1a, $6.1 \mathrm{~g}, 50 \mathrm{mmol}$ ) was dissolved in 1,4-dibromobutane $(30 \mathrm{~mL}, 247 \mathrm{mmol})$. Tetrabutylammonium bromide (TBAB, $0.8 \mathrm{~g} 2.5 \mathrm{mmol}$ ) and $3 \mathrm{M}$ $\mathrm{NaOH}(30 \mathrm{~mL})$ were added and the reaction mixture was stirred and heated under reflux for 4 hours under microwave irradiation with a power input of $60 \mathrm{~W}$. After cooling, dichloromethane $(50 \mathrm{~mL})$ was added and the mixture was rinsed with water $(2 \times 25 \mathrm{~mL})$. The organic phase was dried $\left(\mathrm{MgSO}_{4}\right)$ and concentrated. The oily product was purified by silica gel column chromatography $(0 \rightarrow 30 \%$ EtOAc in heptane) to give 4-(4-bromobutoxy)benzaldehyde (3a, $11.4 \mathrm{~g}, 44.3 \mathrm{mmol}, 88.6 \%) . R_{f} 0.5$ (EtOAc/heptane, $1 / 2, \mathrm{v} / \mathrm{v}) .{ }^{1} \mathrm{H}-\mathrm{NMR}\left(500 \mathrm{MHz}, \mathrm{CDCl}_{3}\right): \delta 1.83(m, 4 \mathrm{H})$, $3.33(t, 2 \mathrm{H}, J=3.8), 4.01(t, 2 \mathrm{H}, J=2.8), 6.93(d d$, $\left.2 \mathrm{H}, J_{1}=J_{2}=6.9\right), 7.78\left(d d, 2 \mathrm{H}, J_{1}=J_{2}=7.8\right)$, $9.85(s, 1 \mathrm{H}) .4$-(4-Bromobutoxy)-2-methoxybenzaldehyde (3b, $12.1 \mathrm{~g}, 42.2 \mathrm{mmol}, 84.4 \%)$ and 4-(4-bromobutoxy)-3methoxybenzaldehyde (3c, $11.8 \mathrm{~g}, 41.1 \mathrm{mmol}, 82.2 \%$ ) were prepared using the same procedure with 4-hydroxy-2methoxybenzaldehyde (1b, 7.6 g, $50 \mathrm{mmol}$ ) and 4-hydroxy3-methoxybenzaldehyde $(1 \mathrm{c}, 7.6 \mathrm{~g}, 50 \mathrm{mmol})$ as reagents, respectively. ${ }^{1} \mathrm{H}-\mathrm{NMR}(3 \mathbf{b}): \delta 1.87(m, 4 \mathrm{H}), 3.31(t, 2 \mathrm{H}$, $J=3.7), 3.89(s, 3 \mathrm{H}), 4.11(t, 2 \mathrm{H}, J=2.8), 6.47(d, 1 \mathrm{H}$, $J=7.2), 6.61(d, 1 \mathrm{H}, J=7.2), 7.89(s, 1 \mathrm{H}), 10.31(s, 1 \mathrm{H})$. ${ }^{1} \mathrm{H}-\mathrm{NMR}(3 \mathrm{c}): \delta 1.89(\mathrm{~m}, 4 \mathrm{H}), 3.28(t, 2 \mathrm{H}, J=3.8), 3.84(s$, $3 \mathrm{H}), 4.07(t, 2 \mathrm{H}, J=2.8), 6.76(d, 1 \mathrm{H}, J=7.2), 7.12(s, 1 \mathrm{H})$, $7.38(d, 1 \mathrm{H}, J=8.3), 10.10(s, 1 \mathrm{H})$.

4.1.2. Benzaldehyde-Functionalized Ionic Liquids $(\mathbf{4 a}-\boldsymbol{c})$. 4(4-Bromobutoxy)benzaldehyde 3a $(5.04 \mathrm{~g}, 20 \mathrm{mmol})$ was dissolved in $\mathrm{CH}_{3} \mathrm{CN}(20 \mathrm{~mL})$ and was treated with $N$-methyl imidazole $(4.0 \mathrm{~mL}, 50 \mathrm{mmol})$ for 2 hours at reflux under microwave irradiation with a power input of $60 \mathrm{~W}$. The mixture was concentrated and the crude product was rinsed with $\mathrm{Et}_{2} \mathrm{O}(2 \times 15 \mathrm{~mL})$ dried under vacuum at $60^{\circ} \mathrm{C}$ for 24 hours to give benzaldehyde-functionalized ionic liquid $\mathbf{4 a}$ (6.64 g, $19.6 \mathrm{mmol}, 98 \%) .{ }^{1} \mathrm{H}-\mathrm{NMR}\left(500 \mathrm{MHz}, \mathrm{CD}_{3} \mathrm{OD}\right): \delta$ $1.77(m, 2 \mathrm{H}), 1.89(m, 2 \mathrm{H}), 3.69(t, 2 \mathrm{H}, J=3.8), 3.91(s$, $3 \mathrm{H}), 4.19(t, 2 \mathrm{H}, J=2.9), 6.81(d, 1 \mathrm{H}, J=5.3), 6.93(d, 1 \mathrm{H}$, $J=5.3), 7.09\left(d d, 2 \mathrm{H}, J_{1}=J_{2}=7.8\right), 7.36(s, 1 \mathrm{H}), 7.78(d d$, $\left.2 \mathrm{H}, J_{1}=J_{2}=8.2\right), 9.92(s, 1 \mathrm{H})$. Ionic liquids $(\mathbf{4 b}, \mathbf{4 c})$ were synthesized using a similar procedure. ${ }^{1} \mathrm{H}-\mathrm{NMR}(\mathbf{4 b}, 97 \%$ yield): $\delta 1.82(m, 2 \mathrm{H}), 1.98(m, 2 \mathrm{H}), 3.60(t, 2 \mathrm{H}, J=3.7)$, $3.72(s, 3 \mathrm{H}), 3.87(s, 3 \mathrm{H}), 4.03(t, 2 \mathrm{H}, J=3.8), 6.89(d, 2 \mathrm{H}$, $J=5.1), 7.23-7.35(m, 3 \mathrm{H}), 7.71\left(d d, 1 \mathrm{H}, J_{1}=J_{2}=7.8\right)$, $10.21(s, 1 \mathrm{H}) .{ }^{1} \mathrm{H}-\mathrm{NMR}(4 \mathrm{c}, 99 \%$ yield $): \delta 1.87(\mathrm{~m}, 2 \mathrm{H}), 2.03$ $(m, 2 \mathrm{H}), 3.63\left(t, 2 \mathrm{H}, J_{1}=J_{2}=3.7\right), 3.78(s, 3 \mathrm{H}), 3.95(s$, $3 \mathrm{H}), 4.21\left(t, 2 \mathrm{H}, J_{1}=J_{2}=2.9\right), 6.67(d, 2 \mathrm{H}), 6.89(d d, 1 \mathrm{H}$, $\left.J_{1}=J_{2}=7.2\right), 7.19(s, 1 \mathrm{H}), 7.31\left(d d, 1 \mathrm{H}, J_{1}=J_{2}=7.8\right), 7.48$ $(s, 1 \mathrm{H}), 9.92(s, 1 \mathrm{H})$.

\subsection{Functional Group Transformation of Ionic Liquids}

4.2.1. Oxidation of Ionic Liquids $(\mathbf{4} \boldsymbol{a}-\boldsymbol{c})$. The typical procedure is presented as follows. Aqueous hydrogen peroxide $(30 \%, 2.4 \mathrm{~mL}, 24 \mathrm{~mol})$ was added dropwise to a stirred solution of $50 \%$ aq. $\mathrm{KOH}(1.0 \mathrm{~mL}, 13.6 \mathrm{mmol})$ and ionic liquid $4 \mathrm{a}(1.02 \mathrm{~g}, 3 \mathrm{mmol})$ in methanol $(5 \mathrm{~mL})$ under reflux for $10 \mathrm{~min}$. Then the mixture was stirred at the same temperature for $30 \mathrm{~min}$, cooled, and acidified with concentrated hydrochloride to give carboxyl-functionalized ionic liquid $\mathbf{5 a}$ (0.95 g, $2.68 \mathrm{mmol}, 89 \%) .{ }^{1} \mathrm{H}-\mathrm{NMR}\left(500 \mathrm{MHz}, \mathrm{CD}_{3} \mathrm{OD}\right): \delta$ $1.72(m, 2 \mathrm{H}), 1.81(m, 2 \mathrm{H}), 3.61(t, 2 \mathrm{H}, J=3.8), 3.79(s$, $3 \mathrm{H}), 4.13(t, 2 \mathrm{H}, J=2.8), 6.62(d, 1 \mathrm{H}, J=5.4), 6.83$ $(d, 1 \mathrm{H}, J=5.4), 7.03\left(d d, 2 \mathrm{H}, J_{1}=J_{2}=7.8\right), 7.30(s$, $1 \mathrm{H}), 8.53\left(d d, 2 \mathrm{H}, J_{1}=J_{2}=8.3\right), 10.78(s, 1 \mathrm{H})$. IR $(\mathrm{KBr})$ : $1705 \mathrm{~cm}^{-1}(\mathrm{C}=\mathrm{O}), 2740 \mathrm{~cm}^{-1}$ (H-bonded, O-H stretching).

4.2.2. Reduction of Ionic Liquids $(\mathbf{4} \boldsymbol{a}-\boldsymbol{c})$. The typical procedure is presented as follows. Aqueous $\mathrm{NaBH}_{4}(10 \%, 4.5 \mathrm{~mL}$, $12.8 \mathrm{mmol}$ ) was added dropwise to a stirred solution of ionic liquid $4 \mathbf{a}(1.02 \mathrm{~g}, 3 \mathrm{mmol})$ in methanol $(5 \mathrm{~mL})$ at room temperature for $10 \mathrm{~min}$. Then the mixture was stirred for 2 hours and acidified with $5 \%$ hydrochloride to give benzyl alcohol-functionalized ionic liquid $\mathbf{6 a}(0.97 \mathrm{~g}, 2.84 \mathrm{mmol}$, 95\%). ${ }^{1} \mathrm{H}-\mathrm{NMR}\left(500 \mathrm{MHz}, \mathrm{CD}_{3} \mathrm{OD}\right): \delta 1.72(m, 2 \mathrm{H}), 1.83$ $(m, 2 \mathrm{H}), 2.37(t, 1 \mathrm{H}), 3.69(t, 2 \mathrm{H}, J=3.6), 3.78(s, 3 \mathrm{H})$, $3.98(t, 2 \mathrm{H}, J=3.8), 4.83(d, 2 \mathrm{H}, J=4.7), 6.77-6.83(\mathrm{~m}$, $4 \mathrm{H}), 7.11\left(d d, 2 \mathrm{H}, J_{1}=J_{2}=7.9\right), 7.36(s, 1 \mathrm{H})$. IR $(\mathrm{KBr})$ : $1050 \mathrm{~cm}^{-1}$ (C-OH stretching), $3310 \mathrm{~cm}^{-1}$ (O-H stretching).

4.2.3. Condensation Reaction of $\mathbf{4 a}$ with Hydrazine. Aqueous $\mathrm{N}_{2} \mathrm{H}_{4} \cdot \mathrm{H}_{2} \mathrm{O}(25 \%, 2.0 \mathrm{~mL}, 10.3 \mathrm{mmol})$ and a catalytic amount of glacial acetic acid were added to a stirred solution of ionic liquid $4 \mathbf{a}(1.02 \mathrm{~g}, 3 \mathrm{mmol})$ in methanol $(5 \mathrm{~mL})$. Then the mixture was heated under reflux for 2 hours, cooled, and concentrated with a rotary evaporator under vacuum to give hydrazone-functionalized ionic compound $7 \mathbf{a}(0.98 \mathrm{~g}$, $2.78 \mathrm{mmol}, 93 \%) .{ }^{1} \mathrm{H}-\mathrm{NMR}\left(500 \mathrm{MHz}, \mathrm{CD}_{3} \mathrm{OD}\right): \delta 1.69(\mathrm{~m}$, $2 \mathrm{H}), 1.78(m, 2 \mathrm{H}), 2.87(s, 2 \mathrm{H}), 3.70(s, 3 \mathrm{H}), 3.83(t, 2 \mathrm{H}$, $J=3.7), 4.01(t, 2 \mathrm{H}, J=2.6), 6.67-6.74(m, 4 \mathrm{H}), 7.36(s$, 
$1 \mathrm{H}), 7.61\left(d d, 2 \mathrm{H}, J_{1}=J_{2}=8.2\right), 8.22(s, 1 \mathrm{H})$. IR $(\mathrm{KBr})$ : $1674 \mathrm{~cm}^{-1}(-\mathrm{C}=\mathrm{N}), 3440 \mathrm{~cm}^{-1}(\mathrm{~N}-\mathrm{H}$ stretching $)$.

4.2.4. Reductive Amination of $\mathbf{4 a}$ with Aniline. Aniline $(0.3 \mathrm{~mL}, 3.3 \mathrm{mmol})$ and $4 \mathrm{a}(1.02 \mathrm{~g}, 3 \mathrm{mmol})$ were mixed in ethanol $(5 \mathrm{~mL})$ and the reaction mixture was stirred at $60^{\circ} \mathrm{C}$ for $60 \mathrm{~min}$ followed by the addition of sodium borohydride $(0.175 \mathrm{~g}, 4.5 \mathrm{mmol})$ for another $60 \mathrm{~min}$, cooled, and concentrated with a rotary evaporator under vacuum. The remainder was solubilized in acetonitrile $(10 \mathrm{~mL})$ and filtered to separate sodium borohydride. The acetonitrile solution was dried $\left(\mathrm{MgSO}_{4}\right)$ and concentrated to give compound 8a (1.05 g, $2.53 \mathrm{mmol}, 84 \%$ ). ${ }^{1} \mathrm{H}-\mathrm{NMR}$ (500 MHz, CD $\left.3 \mathrm{OD}\right): \delta$ $1.67(m, 2 \mathrm{H}), 1.79(m, 2 \mathrm{H}), 2.07(s, 1 \mathrm{H}), 3.69(s, 3 \mathrm{H}), 3.78-$ $3.83(m, 6 \mathrm{H}), 4.07(t, 2 \mathrm{H}, J=3.8), 6.61-6.73(m, 4 \mathrm{H}), 6.93-$ $7.07(m, 5 \mathrm{H}), 7.26\left(d d, 2 \mathrm{H}, J_{1}=J_{2}=8.2\right), 7.42(s, 1 \mathrm{H})$. IR ( $\mathrm{KBr}): 3370 \mathrm{~cm}^{-1}(\mathrm{~N}-\mathrm{H}$ stretching).

\section{Acknowledgments}

The authors are grateful to the financial support from Science and Research Foundation of Yunnan University (Grant no. 2010YB045) and that of Yunnan Province Education Department (Grant no. 2011Z017), and the samples testing services from Advanced Analysis and Measurement Center of Yunnan University.

\section{References}

[1] H. Olivier-Bourbigou and L. Magna, "Ionic liquids: perspectives for organic and catalytic reactions," Journal of Molecular Catalysis A, vol. 182-183, pp. 419-437, 2002.

[2] Q. Huang, L. Wang, B. Zheng, and Q. Long, "Green organic reactions in phosphonium salt ionic liquid Media," Progress in Chemistry, vol. 21, no. 9, pp. 1782-1791, 2009.

[3] X. Han and D. W. Armstrong, "Ionic liquids in separations," Accounts of Chemical Research, vol. 40, no. 11, pp. 1079-1086, 2007.

[4] D. R. Macfarlane, M. Forsyth, P. C. Howlett et al., "Ionic liquids in electrochemical devices and processes: managing interfacial electrochemistry," Accounts of Chemical Research, vol. 40, no. 11, pp. 1165-1173, 2007.

[5] M. Antonietti, D. Kuang, B. Smarsly, and Y. Zhou, "Ionic liquids for the convenient synthesis of functional nanoparticles and other inorganic nanostructures," Angewandte ChemieInternational Edition, vol. 43, no. 38, pp. 4988-4992, 2004.

[6] Z. Li, Z. Jia, Y. Luan, and T. Mu, "Ionic liquids for synthesis of inorganic nanomaterials," Current Opinion in Solid State and Materials Science, vol. 12, no. 1, pp. 1-8, 2008.

[7] T. Welton, "Room-temperature Iionic liquids. Solvents for synthesis and catalysis," Chemical Reviews, vol. 99, no. 8, pp. 2071-2083, 1999.

[8] K. R. Seddon, "Ionic liquids for clean technology," Journal of Chemical Technology and Biotechnology, vol. 68, no. 4, pp. 351356, 1997.

[9] H. L. Ngo, K. LeCompte, L. Hargens, and A. B. McEwen, "Thermal properties of imidazolium ionic liquids," Thermochimica Acta, vol. 357-358, pp. 97-102, 2000.

[10] R. Giernoth, "Task-specific ionic liquids," Angewandte Chemie-International Edition, vol. 49, no. 16, pp. 2834-2839, 2010.
[11] M. Pucheault and M. Vaultier, "Task specific ionic liquids and task specific onium salts," Topics in Current Chemistry, vol. 290, pp. 83-126, 2009.

[12] W. Miao and H. C. Tak, "Ionic-liquid-supported synthesis: a novel liquid-phase strategy for organic synthesis," Accounts of Chemical Research, vol. 39, no. 12, pp. 897-908, 2006.

[13] G. Song, Y. Cai, and Y. Peng, "Amino-functionalized ionic liquid as a nucleophilic scavenger in solution phase combinatorial synthesis," Journal of Combinatorial Chemistry, vol. 7, no. 4, pp. 561-566, 2005.

[14] Y. Cai, Y. Zhang, Y. Peng, F. Lu, X. Huang, and G. Song, "Carboxyl-functional ionic liquids as scavengers: case studies on benzyl chloride, amines, and methanesulfonyl chloride," Journal of Combinatorial Chemistry, vol. 8, no. 5, pp. 636-638, 2006.

[15] H. Luo, S. Dai, P. V. Bonnesen, and A. C. Buchanan, "Separation of fission products based on ionic liquids: taskspecific ionic liquids containing an aza-crown ether fragment," Journal of Alloys and Compounds, vol. 418, no. 1-2, pp. 195199, 2006.

[16] P. Nockemann, B. Thijs, T. N. Parac-Vogt et al., "Carboxylfunctionalized task-specific ionic liquids for solubilizing metal oxides," Inorganic Chemistry, vol. 47, no. 21, pp. 9987-9999, 2008.

[17] Q. T. Wang, X. B. Wang, W. J. Lou, and J. C. Hao, "Stable blue- and green-emitting zinc oxide from ionic liquid crystal precursors," Chemphyschem, vol. 10, no. 18, pp. 3201-3203, 2009.

[18] X. L. Tao, M. Lei, and Y. G. Wang, "Ionic liquid supported synthesis of $\beta$-lactam library in ionic liquid batch," Tetrahedron Letters, vol. 48, no. 29, pp. 5143-5146, 2007.

[19] J. Fraga-Dubreuil and J. P. Bazureau, "Grafted ionic liquidphase-supported synthesis of small organic molecules," Tetrahedron Letters, vol. 42, no. 35, pp. 6097-6100, 2001.

[20] S. S. Panda, P. Khanna, and L. Khanna, "Biginelli reaction: a green perspective," Current Organic Chemistry, vol. 16, pp. 507-520, 2012.

[21] A. Ouach, M. Pucheault, and M. Vaultier, "Onium salt supported organic synthesis in water: application to ugi's 4-components reaction," Heterocycles, vol. 73, pp. 461-467, 2007.

[22] A. Ouach, S. Gmouh, M. Pucheault, and M. Vaultier, "Onium salt supported organic synthesis in water: application to Grieco's multicomponent reaction," Tetrahedron, vol. 64, no. 8, pp. 1962-1970, 2008.

[23] E. E. Swayze, "Secondary amide-based linkers for solid phase organic synthesis," Tetrahedron Letters, vol. 38, no. 49, pp. 8465-8468, 1997.

[24] M. Guinó and K. K. Hii, "Wang-aldehyde resin as a recyclable support for the synthesis of $\alpha, \alpha$-disubstituted amino acid derivatives," Organic and Biomolecular Chemistry, vol. 3, no. 17, pp. 3188-3193, 2005.

[25] A. M. Fivush and T. M. Willson, "AMEBA: an acid sensitive aldehyde resin for solid phase synthesis," Tetrahedron Letters, vol. 38, no. 41, pp. 7151-7154, 1997.

[26] Q. Huang, B. Z. Zheng, and Q. Long, "Development of 3-methoxy-4-benzyloxybenzyl alcohol (MBBA) resin as polymer-supported synthesis support: preparation and benzyl ether cleavage by DDQ oxidation," Journal of Chemical Sciences, vol. 122, no. 2, pp. 203-207, 2010.

[27] G. D. Yadav and P. M. Bisht, "Novelties of microwave assisted liquid-liquid phase transfer catalysis in enhancement of rates and selectivities in alkylation of phenols under mild 
conditions," Catalysis Communications, vol. 5, no. 5, pp. 259263, 2004.

[28] P. Lidström, J. Tierney, B. Wathey, and J. Westman, "Microwave assisted organic synthesis-a review," Tetrahedron, vol. 57, no. 45, pp. 9225-9283, 2001.

[29] Z. Q. Cong, C. I. Wang, T. Chen, and B. Z. Yin, "Efficient and rapid method for the oxidation of electron-rich aromatic aldehydes to carboxylic acids using improved basic hydrogen peroxide," Synthetic Communications, vol. 36, no. 5, pp. 679683, 2006. 


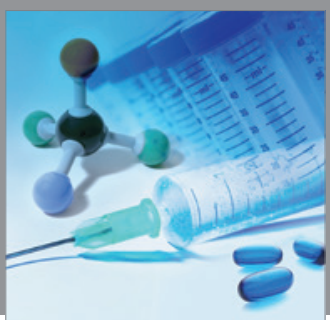

International Journal of

Medicinal Chemistry

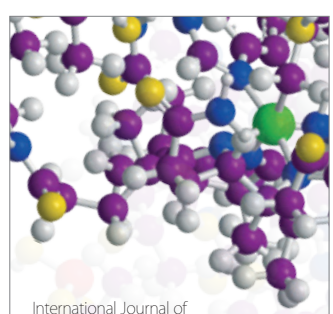

Carbohydrate Chemistry

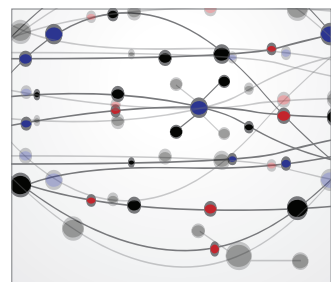

The Scientific World Journal
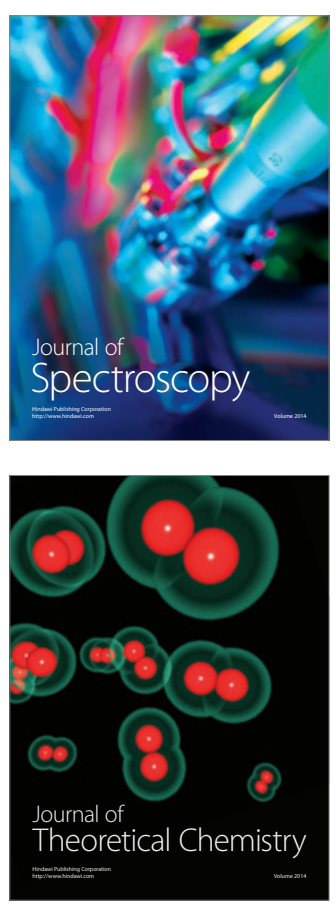
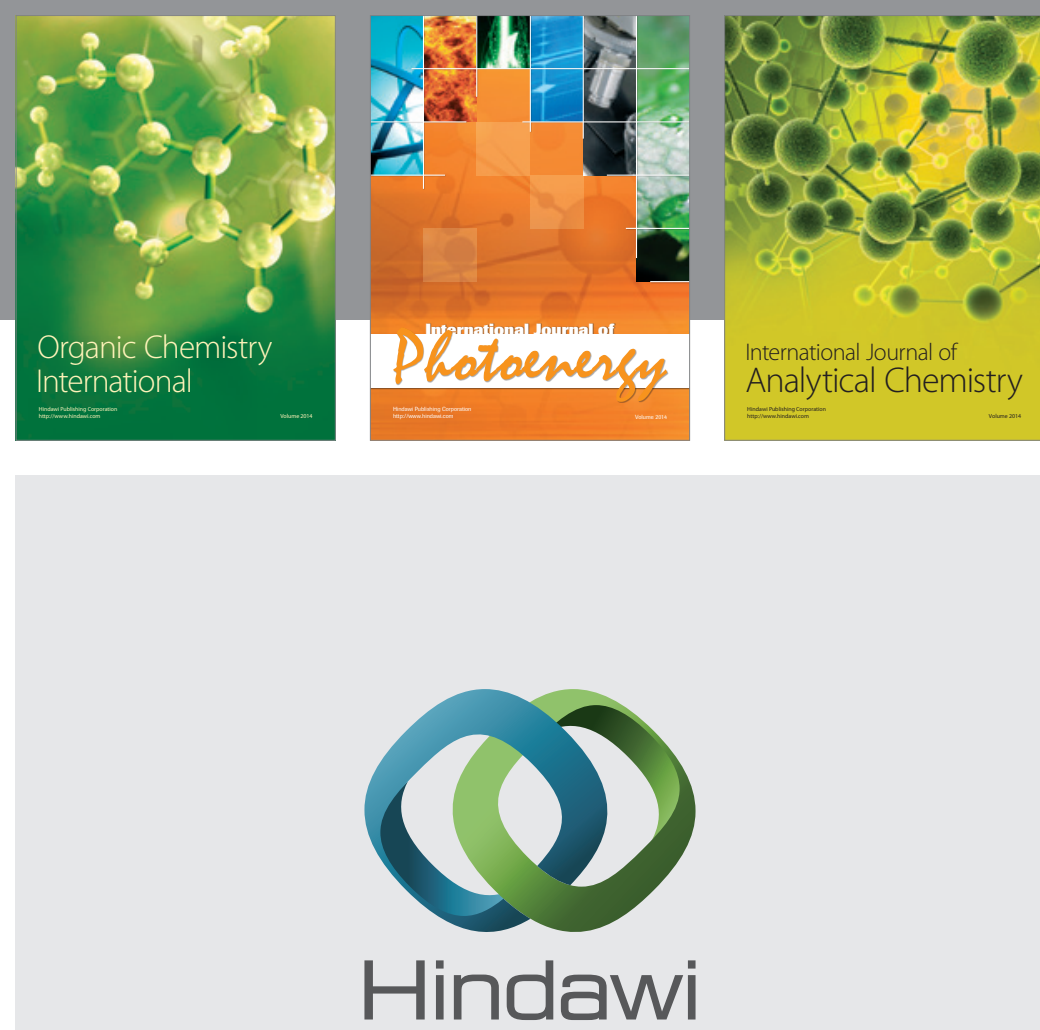

Submit your manuscripts at

http://www.hindawi.com
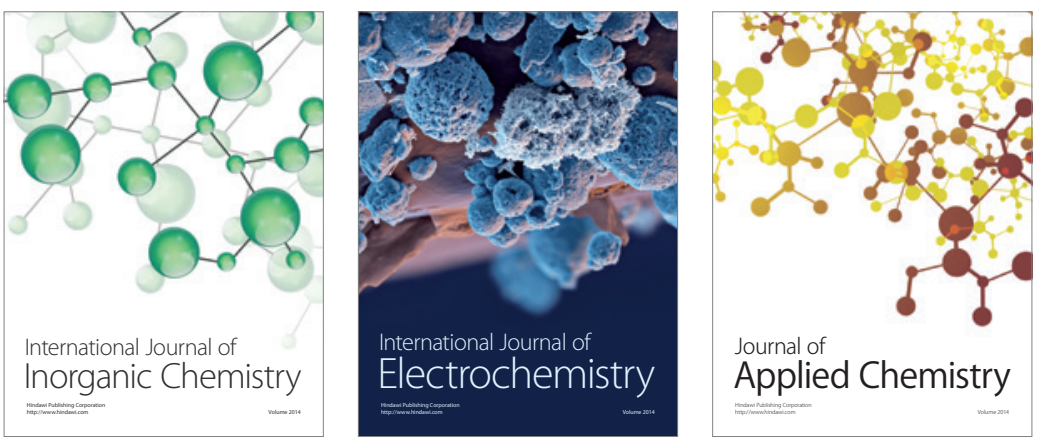

Journal of

Applied Chemistry
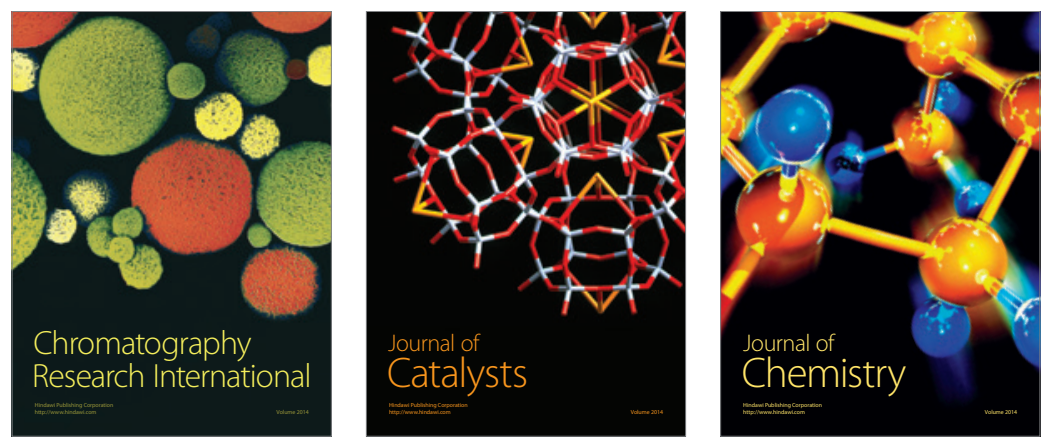
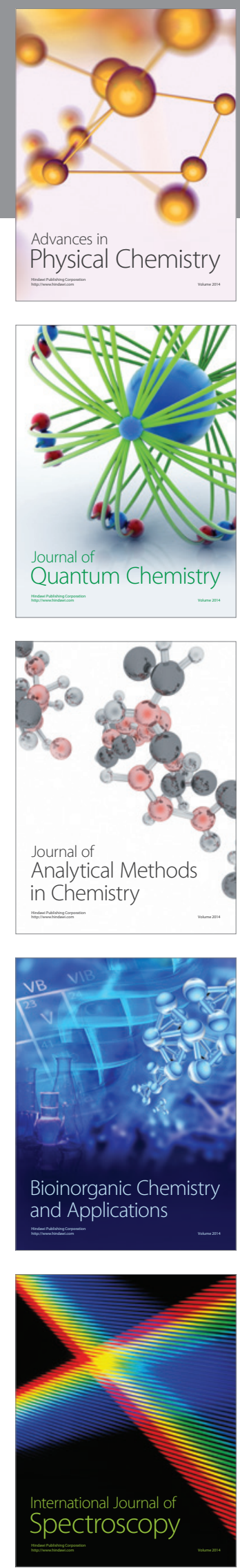